UDK: 659.122:177.61]:[[82-1(292.553)“06“]:HEINE H. Izvorni naučni rad

Primljeno: 14. 6. 2021.

Prihvaćeno za štampu: 21. 11. 2021.

Dr. sc. Semir Rebronja, vanr. prof.

Islamski pedagoški fakutet Univerziteta u Zenici

E-mail: r_semir@yahoo.com

\title{
MOTIV LJUBAVI KOD UZRITSKIH PJESNIKA I HAJNRIHA HAJNEA
}

\section{Sažetak}

Predmet istrą̌ivanja ovog rada jeste komparativna analiza urritske $i$ Hajneove lirike $i$ shodno tome ispitati rąloge $i$ zajedničke činioce dviju knjiž̌evnosti, jedne u pustinji, a druge u Evropi. Analizom pjesama Mağnūna i Ğamila, sjedne strane, i Hajnea, s druge strane, dokazujemo vrlo bliske teme o ljubavi, kao i o pjesnickom "pesimizmu“. Pjesma Der Asra pjesnika Hajnea je bila pod utjecajem arapskih urritskib pjesnika. Ona se nalazi kao 15. pjesma u Hajneovom serijalu Romanse i balade, a nastala je u periodu oko 1845/46. godine. Pjesma Azra govori o Uzritima. Hajne je našao inspiracije $u$ arapskim anegdotama o urritskoj ljubavi, koje je ritao u čuvenoj Stendalovoj knjizi „O ljubavi" (De l'amor, iz 1822. godine). Osnovna tema o kojoj urritski pjesnik pjeva je ljubav, žena i to samo jedna žena koja je obuzela njegovo srce. Ta žena je materijalizacija svih pjesnikovih želja, ciljeva i stremljenja. Ona je centar njegovog pjevanja, i ne samo pjevanja, ona je centar pjesnikovog svijeta. Hajneov zaljubljenik je usamljen, onaj koji čezne. To je čežnja za daljinom. On je tu svoju č そ̌nju personifikovao u boru, usamljenom, na sjeveru, koji žndi za palmom koja je daleko, negdje na istoku, u pustinjskom pijesku.

Ključne riječi: uæritska poezija, romantizam, Hajnrib Hajne, komparativna književnost

\section{UVOD}

Uzritska poezija je novi, u formi, jeziku, stilu i obradi teme, jedinstveni književni pokret nastao na Arapskom poluotoku u VII vijeku. Uzritska poezija je poezija arapske pustinje. To je poezija u kojoj beduinski 
pjesnik iskazuje svoja iskristalisana i istančana osjećanja ljubavi, čežnje, ljubavnog žara i boli prema svojoj dragoj, jedinom cilju svih njegovih stremljenja, ali, ujedno, i jedinom izvoru njegovog bola $\mathrm{i}$ patnje. To je poezija čiste, nepatvorene, ali stilizovane platonske nematerijalizovane ljubavi, koja nagoni pjesnika da luta pustinjskim prostranstvima, goneći svoje stado, pjeva o svojoj dragoj, a nerijetko, zanesen tom ljubavlju gubi i razum.

U književno-teorijskoj literaturi gazel (al-ġazal, al- gazal al-udrī, uzritski gazel, uzritska ljubavna pjesma) se najčešće definira kao lirska ljubavna pjesma, koja se sastoji od distiha (al-bayt) čiji broj varira između pet i petnaest. To je tužna pjesma o ljubavi, često erotskoelegijskog karaktera. Termin je arapskog porijekla, ali se upotrebljava i u perzijskoj, turskoj i urdu književnosti te u njihovim jezicima ima posebno značenje. ${ }^{1}$

U definisanju ove riječi ćemo se poslužiti nekim od najznačajnijih arapskih leksikografskih ostvarenja. Kada je ova pjesnička vrsta u pitanju, nužno je osvrnuti se na semantički razvoj ove riječi. Njen korijen sačinjen je od triju suglasnika g-z-l od kojeg je i gazala (gazala), glagol koji upućuje na zabavljanje, ljubavni razgovor, ukazuje na pjesmu mladića upućenu djevojci. ${ }^{2}$

Romantizam je književni pokret koji se u posljednjim decenijama XVIII i prvoj polovini XIX vijeka proširio u Evropi. Prvi koji su o romantizmu počeli govoriti označivši stil i pravac, bili su braća S̆legel. ${ }^{3}$

Pokrenut društveno-političkim faktorima toga vremena, prije svega Francuskom revolucijom i dešavanjima u Evropi, u Njemačkoj se u zadnjim decenijama XVIII vijeka, godine 1870. javlja romantizam koji je, u znatnoj mjeri, predstavljao njemački ekvivalent Francuskoj revoluciji. Umjetničko stvaralaštvo je istog značaja kao i politička aktivnost, ističe Šlegel, smatrajući da filozofski i književni tekstovi nisu

\footnotetext{
${ }^{1}$ Bernard Lewis, The Encyclopaedia of Islam, Leiden, E.J. Brill, 1991., str. 2/1028.

${ }^{2}$ Bernard Lewis, prethodni izvor, str. 2/1028-1029.

3 Tanja Popović, Rečnik književnih termina. Beograd: Logos Art, str. 634.
} 
ništa manje djelotvorni nosioci duhovne revolucije od političkog prevrata. ${ }^{4}$

Svojevremeno je romantizam u Evropi shvaćen, prije svega, kao njemački pravac i u njegovom razvoju zapažamo nekoliko etapa kroz koje je prošao. Kao preteče romantizmu u Njemačkoj nalazimo romantičarske i predromantičarske ideje još od pokreta buntovnih genija (Sturm und Drang), da bi se romantizam, kao književni pravac, manifestovao u više književnih centara, od kojih su bili najznačajniji Jena i Hajdelberg. ${ }^{5}$

Glavni teoretičari njemačkog romantizma bili su Herder i braća Šlegel, ali se njihov pogled na romantizam znatno razlikovao. Herder stvara novu kulturu u kojoj polazi od nacionalne specifičnosti duhovnog stvaralaštva, dok braća Šlegel, vaspitani na principima klasičnog duha prosvjetiteljstva i antičke baštine, polaze od evropske književnosti kao cjeline, ukazujući i na vrijednost Istoka i potrebe da se Evropa s njima upozna putem prevoda. ${ }^{6}$

No, kako nam ovdje nije cilj govoriti o karakteristikama njemačkog romantizma, jer to i nije tema ovog rada, već isključivo jedan od njegovih kasnijih predstavnika, posvetit ćemo naredne stranice njemu i utjecaju koji je Orijent ostavio na ovog autora. Pored Getea, veliki njemački književnik koji je bio pod najsnažnijim utjecajem Orijenta i orijentalne misli, bio je Hajnrih Hajne (Heinrich Heine).

\section{HAJNE I ,ISTOČNI“ MOTIVI}

Prije nego što se posvetimo detaljnijem predočavanju istočnjačkih motiva kod Hajnea, nužno je spomenuti, i to veoma kratko Getea. Utjecaj Istoka na Getea ovde neće biti posebno tretiran iz razloga što je utjecaj perzijske književnosti bio na Getea. Fehim Bajraktarević u opsežnoj studiji Uticaj Istoka na Getea govori opširno o utjecaju, ne samo islamskog već uopće Istoka na djelo i rad Getea, ističući neke

\footnotetext{
${ }^{4}$ Viktor Žmegač, Romantizam, Povijest svjetske književnosti, 104-130, Zagreb, Mladost, str. 105.

${ }^{5}$ Jovan Deretić, Istorija srpske književnosti, 2007., Zrenjanin, Sezam buk, str. 660.

${ }^{6}$ Jovan Deretić, prethodni izvor, str. 661.
} 
značajne elemente, posebno nama bitnog islamskog utjecaja na njegova djela. $^{7}$

Samo u divanu, navodi Bajraktarević, nazvavši to utvrđenom činjenicom, na blizu dvije stotine mjesta ustanovljen je utjecaj Istoka na Getea. ${ }^{8}$

Hajne je rođen krajem XVIII vijeka u Njemačkoj, u jevrejskoj porodici, a počeo je pisati oko 1815. godine. Ono što je bitno naglasiti, to je činjenica, da se Hajnrih Hajne u jesen 1819. godine upisao na Univerzitet u Bonu. Tamo je imao prilike slušati predavanja i stupiti u bliske veze s Avgustom Vilhemom Šlegelom (August Wilhelm Schlegel). ${ }^{9}$ Već smo u tekstu ranije naveli osnovne karakteristike misli braće Šlegel koji su isticali značaj Istoka i njegovih dostignuća i nužnost evropskog upoznavanja s tom baštinom. Očigledno da je mladi Hajne naučio puno od Šlegela i ne samo naučio, već u mnogim segmentima i prihvatio njegovo viđenje romantizma i nužnost da se Evropa upozna s Istokom i istočnom baštinom. On je smatrao da se Evropa treba odreći hrišćansko-germanskog srednjeg vijeka. U ljeto 1820. Hajne je pisao: "Nema više popa koji bi mogao okovati u lance njemačke duhove; nema više plemićkog velmoža koji bi mogao bičem nagnati njemačka tijela na kulučenje; stoga neka i njemačka muza opet bude slobodno, cvjetno, neizvještačeno, časno njemačko djevojče, a ne koludrica koja kopni, ni plemkinja koja se diči svojim precima."10

Koliko je Orijent imao utjecaja na Hajnea vidi se iz jednog njegovog pisma, koje je 14. aprila 1822. godine poslao jednom svom prijatelju. $U$ pismu Hajne govori o tome koliko je Njemačka dosadna i da se želi odseliti u Arabiju, gdje bi živio kao beduin. On u pismu kaže: „Nikad nisam mislio da ove životinje koje se nazivaju Nijemcima, mogu biti u isto vrijeme tako dosadne i podmukle. Čim se moje zdravlje poboljša, napustit ću Njemačku i otići u Arabiju, tamo ću živeti nomadskim životom, i tada ću se u pravom smislu te riječi osjećati kao čovjek, živjet ću među kamilama. Nema studenata koji pišu nešto kao što su arapske

\footnotetext{
${ }^{7}$ Pogledati: Fehim Bajraktarević, Uticaj Istoka na Getea, 1938., Beograd, str. 12-25.

${ }^{8}$ Fehim Bajraktarević, Uticaj Istoka ..., str. 39.

${ }^{9}$ Franc Mehring, Heinrich Heine, 1951., Beograd-Zagreb, str. 9.

${ }^{10}$ Franc Mehring, prethodni izvor, str. 10.
} 
mualake. Konačno ću sjesti na svetoj stijeni na kojoj je Medžnun čeznuo za Lejlom." "11 Hajne je opčaran, između ostalog, Medžnunom i njegovom Lejlom, to je paradigma ljubavi kod Hajnea. Zanimljivo je da Hajne nije bio fasciniran evropskim ljubavnim likovima, već Arapinom, pustinjakom.

Ane Maksimiliane Jegers u svojoj disertaciji Besaß auch in Spanien manch luftiges Schlo $\beta$, (Anne Maximiliane Jägers 1999), George Peters, u djelu Der große Heide (George Peters Nr. 2, 1989), kao i Mounir Fendris u svojoj disertaciji Halbmond, Kreuz und Schibbolleth. Heinrich Heine und der islamische Orient (1980) pružaju jasne dokaze da Orijent za Hajnea nije samon marginalna stvar već da je on zaokupljen njime. Ko poznaje Geteov Zapadno-istočni divan već u prvom stihu Hajneove pjesme Ali bei će prepoznati utjecaj Geteovog orijentalnog duha na Hajnea.

Ali-beg, za veru borac, ${ }^{12}$

U naručju ženskom leži.

Alah mu na zemlji daje

Predukus blaženstva rajskih.

Odaliske, ko hurije

Lepe, ko gazele vitke

Jedna mu kovrča bradu

A druga mu čelo gladi.

Na lauti treća svira,

Peva, pleše, sa smehom mu

Ljubi srce koje plamti

Od zanosa i blaženstva.

Al najednom zatreštaše

Trube, ču se zveket mača,

${ }^{11}$ Heinrich Heine, Briefe, str. 40.

${ }^{12}$ Prevod ove pjesme je preuzet iz izbora pjesama Sve slobode, u prevodu Slobodana Glumca, Beogradski istraživačko-grafički zavod, Beograd, 1975., str. 135. 
Bojni poklik, cik pušaka-

Gospodaru Franci stižu!

Na konja se junak vinu, U boj juri, al' ko u snu; -

Čini mu se da još leži

U naručju devojačkom.

Dok franačke glave rubi

Svojom sabljom, na tuceta,

Smeši se ko zaljubljenik,

Da, blago se, nežno smeši.$^{13}$

U okviru ove teme, naročito interesantna je i njegova čuvena pjesma Der Asra. Ona se nalazi kao 15. pjesma u Hajneovom serijalu Romanse $i$ balade, i nastala je negdje oko 1845/46. godine. Ovu pjesmu susrećemo u prevodu nekolikih prevodilaca, a Otmar Perši (Ottmar Pertschi) nabraja čak trinaest prevoda ove pjesme na jezike Balkana. ${ }^{14}$

Najpoznatiji prevod sačinio je Safvet-beg Bašagić, a Aleksa Šantić je objavio u zbirci prepjeva Hajneovih pjesama iz 1923. godine, u knjizi Iz Hajneove lirike. ${ }^{15}$ Također, nju su prevodili i Dragutin Ilić, Slobodan Glumac, ${ }^{16}$ zatim Dobriša Cesarić, ${ }^{17}$ Branimir Živoinović. ${ }^{18}$

13 Hajnrih Hajne, Sve slobode - izabrane pesme, 1975., Beograd, Beogradski izdavačko-grafički zavod, str. 181.

${ }^{14}$ Ottmar Pertschi, Der Asra - ein bosnische Volkslied und/oder eine Ubersetzung aus Heine?, 2001., Heine-Jahrbuch, str. 132-133.

15 Aleksa Šantić, Iz Hajneove lirike, 1923., Mostar, Knjižarnica Tripka Dudića, str. 138.

${ }^{16}$ Hajnrih Hajne, prethodni izvor, str. 194.

${ }^{17}$ Hajnrih Hajne, Pesme, 1964., Beograd, Rad, str. 23.

${ }^{18}$ Hajnrih Hajne, Bio je divan mesec maj, 1989., Beograd, Bajat, str. 101. 
Hajne je, ističe F. Bajraktarević „našao inspiracije u arapskim anegdotama o uzritskoj ljubavi, koje je čitao u čuvenoj Stendalovoj knjizi O ljubavi (De l'amor, iz 1822. godine). ${ }^{19}$

Hajne je od Stendala preuzeo pogrešnu transkripciju imena ovog plemena i umjesto Uzra (ar. 'Udra) transkribovao kao Azra.

Inače, Stendal je u svojoj knjizi $O$ ljubavi posvetio jedno poglavlje plemenu Benu Uzra, navodeći neke anegdote o zaljubljenosti njegovih pripadnika. Na samom početku, spominje Džemila i Busejnu. On kaže: „Ovaj Džamil i Bothaina, njegova dragana, pripadali su oboje BenuAzra, plemenu slavnom po ljubavi među svim arabljanskim plemenima. Isto tako, način na koji vole, ušao je u poslovicu, a bog nije stvorio tako nježna stvorenja kao što su oni. “20

U nastavku Stendal navodi primjere i anegdote u kojima se spominje legenda o pripadnicima ovog plemena, koji su se predstavljali kao „oni iz plemena Benu Uzra, što umiru od ljubavi“ te je Hajne u svojoj pjesmi Azra vješto ukomponovao ovaj motiv. Pjesma u prijevodu glasi:

Kraj tanana šadrvana, Gdje žubori voda živa, Šetala se svakog dana, Sultanova kćerka mila.

Svakog dana jedno ropče,

Stajalo kraj šadrvana, Kako vr'jeme prolazilo, Sve je bljeđe, bljeđe bilo.

Jednog dana zapita ga, Sultanova kćerka draga:

"Kazuj, robe, odakle si, iz plemena kojega si?"

"Ja se zovem El-Muhammed,

19 Fehim Bajraktarević, Postanak Bašagićeve Ašiklije i problem pozajmica u književnosti, Zbornik Filozofskog fakulteta, 1956., str. 415.

${ }^{20}$ Anri Bejl Stendal, O ljubavi,1976., Subotica, Minerva, str. 185-186. 
iz plemena starih Azra,

što za ljubav život gube, i umiru kada ljube!"21

Najsnažniji pokazatelj njihove ljubavi su stihovi koji govore o praiskonskoj ljubavi, o ljubavi prije rođenja, o sudbinskoj predodređenosti jednog za drugo. Takva ljubav je identična i kod Hajnea ali i uzritskih pjesnika, Medžuna i Džemila:

Moja duša je s njenom spojena, još prije našeg stvaranja, A $i$ nakon što smo sjemena kap u utrobama postali.

Kako smo rasli, $i$ ona je s nama rasla i stasavala, Pa i ako mi umremo te ljubavi neće nestati. ${ }^{22}$ A s druge strane Džemil (Ğamīl) pjeva:

Zbog nje me je prekorio brat, meni blizak čovjek, Voljeni prijatelj u čijem savjetu za mene je razum,

Govoraše mi: Probudi se, do kada ćeš maštati, Busejna niti će doći, niti će se vratiti.

Odgovor moj bješe: Sudba Božija mi je tako htjela A ima li koga da sudbi Božijoj mogaše reći - Ne? ${ }^{23}$

Smrt je samo sekvenca, iz pojavnog u nepoznato, ali nije, niti će nestati, i u pjesmama Hajnea, kao i Medžuna i Džemila je vidljivo.

Pored ove dvije pjesme, Hajne je svoju zadivljenost Istokom i istočnom poezijom iskazao i u pjesmi o pjesniku Firdusiju, ${ }^{24}$ za koju je, navodi

\footnotetext{
${ }^{21}$ Aleksa Šantić, Iz Hajneove lirike, str. 138.

${ }^{22}$ Mağnūn, Dīwân. Bayrūt: Dâr al-ma'rifa, str. 136.

${ }^{23}$ Ğamīl, Dīwân. Bayrūt: Dâr al-râtib al-ğami'iyya, str. 65.

${ }^{24}$ Prevod ove pjesme je preuzet iz knjige Pesma - Hajnrih Hajne, u prevodu Hinka Gotliba.
} 
F. Bajraktarević, uzeo materijal od Hamera. ${ }^{25}$ On opisuje djelo Šahname i kaže:

Tako misle dobri ljudi,

To mnijaše i Firdusi,

Autor obožavanoga

Djela slavnog , Š̆ name“26

U kontekstu utjecaja arapskih anegdota i priči o čistoj ljubavi, ljubavnom bolu i patnjama zaljubljenog, važno je istaći da je u Hajneovoj ljubavnoj lirici načinjen ozbiljan zaokret u shvatanju ljubavi u odnosu na ono što je ona bila kod ranijih romantičara. Za Hajnea ljubav postaje bol,. To je ta „mala tema“ oko koje se vrti cjelokupno Hajneovo pjevanje u Knjizi pesama koja predstavlja njegovo najznačajnije djelo. U svim tim pjesmama čitalac se susreće sa zaljubljenim mladićem rastrzanim između čežnje za voljenom osobom i bola zbog njenog gubitka. ${ }^{27}$

Interesantno je njegovo izjednačavanje ljubavi i bola u Lirskom intermecu u 21. pjesmi, gdje kaže:

Ne znam beše li ljubav veća ili bol vreo?

Samo znam da sam jednako s oboje mreo. ${ }^{28}$

Hajneov ljubavnik, kao i uzritski pjesnik osuđen je na izolovanost i izdvojenost iz zajednice. On je, obično, individua, potpuno posvećena svom ljubavnom bolu, svojoj ljubavi. Za njega skoro da ne postoji ništa oko njega, a i ono što postoji, postoji isključivo radi toga da svjedoči njegovu ljubavnu bol i patnju. Uzritski pjesnici su idealizirali ljubavnu bol. ${ }^{29}$

${ }^{25}$ Fehim Bajraktarević, Postanak Bašagićeve Asiklije..., str. 415.

${ }^{26}$ Prevod ove pesme je preuzet iz knjige Pesma - Hajnrih Hajne, u prevodu Hinka Gotliba.

27 Mirko Krivokapić, Nemačka književnost - članci $i$ rasprave, 2011., Sremska Mitrovica-Novi Sad, str. 171.

${ }^{28}$ Aleksa Šantić, Pesme, str. 158.

${ }^{29}$ Zanimljivo da se u rječniku Tadžu al-arusa (Tāğ al-'arūs) za ljubav kaže: „Ahaba al-bair (Ahabba al-b'aīr) - za devu koja legne i neće ustati. To je ona deva koja, uslijed bolesti, legne na zemlju i ne može ustati u takvom stanju ostaje sve dok ne umre ili 
Medžun pjeva:

Kada će se izliječiti od tebe srce ranjeno?

Od tebe su mi bliže strijele smrti.

Ostaje mi samo daljina, ljubavni bol, čežnja, drhtaj...

Ti mi ne dolaziš, a ja ti se ne mogu približiti. ${ }^{30}$

I u Hajnevoj pjesmi, kao i Medžunovoj, identične su teme, kao što su ljubavna bol, smrt i sl.

U svom Intermecu, Hajne, pjeva:

I kada bi ljubice male,

bol moga srca znale,

sa mnom bi plakale one,

da rane blaže mi bone.

I kada bi slavuj u lugu,

znao za moju tugu,

pjesme bi zapjevô lijepe

što teše i srce krepe. ${ }^{31}$

Hajneov zaljubljenik je usamljen, onaj koji čezne. To je čežnja za daljinom. On je tu svoju čežnju personifikovao u boru, usamljenom, na sjeveru, koji žudi za palmom koja je daleko, negdje na Istoku, u pustinjskom pijesku. Ova pjesma govori o pjesnikovoj otuđenosti i žudnji za nekim drugim svijetom, a mi se usuđujemo kazati s obzirom na to da je pisana u približno vrijeme kada i već spomenuto pismo koje je Hajne uputio jednom svom prijatelju, da, možda krije pjesnikovu želju za Istokom, gdje sebe predstavlja kao usamljen bor na sjeveru,

bude izliječena. (Al-Zabīīi, Tağ al-arūs. Kuwayt: Wizarāt al-iršād we al-anbā' fi alKuwayt, str. 3/220.)

${ }^{30}$ Mağnūn, prethodni izvor, str. 16.

${ }^{31}$ Aleksa Šantić, Pesme, str. 160. 
usamljen u sredini u kojoj živi, hladnoj, dalekoj od ljudskih osjećanja i boli, koji žudi za ljubavlju Istoka, i sanja o toj nepremostivoj daljini.

Bor usamljen na severu

Stoji navrh gola brega.

Drema mu se; belim plaštom

Led sa snegom ogrće ga.

On o jednoj palmi sanja

Sred istočne daljne strane,

Što samotna nemo tuži

Navrh stene usijane. ${ }^{32}$

Uzritski pjesnik pjeva o ljubavi prema svojoj voljenoj. Njegovo pjevanje je ispunjeno bolom i tugom, čežnjom za voljenom, ali, u isto vrijeme, to osjećanje ljubavi je uokvireno i određeno kontekstima vremena i prostora. Osnovna tema o kojoj uzritski pjesnik pjeva je ljubav, žena i to samo jedna žena koja je obuzela njegovo srce. Ta žena je materijalizacija svih pjesnikovih želja, ciljeva i stremljenja. Ona je centar njegovog pjevanja i ne samo pjevanja, ona je centar pjesnikovog svijeta.

\section{ZAKLJUČAK}

Prekretnica u razvoju evropske književnosti sa stanovišta promovisanja nekih novih književnih ideja i formi jeste period romantizma. Snažan utjecaj na razvoj cjelokupnog evropskog romantizma ima njemački romantizam, te je to i bio razlog zbog kojeg smo posvetili upravo utjecaju jednog od najznačajnijih njemačkih književnika, poznog romantičara Hajnriha Hajnea. U radu je primarno mjesto dato Hajneu, iako je rad u kratkim crtama tretirao i utjecaj koji je Istok ostavio na Getea. Gete, inače, nije bio posebna tema ovog istraživanja iz razloga

${ }^{32}$ Aleksa Šantić, Pesme, str. 163. 
što je kod njega, prije svega, primjetan utjecaj Hafiza i perzijske književnosti.

Sam Hajne je u mnogim svojim pjesama, pa i proznim djelima, isticao oduševljenje Istokom $\mathrm{i}$ prezir prema onome što je doživljavao u Njemačkoj. Razlog tome treba tražiti u oduševljenju koje je Hajne, čitajući neka djela u kojima je prezentovana arapsko-islamska književnost osjetio ideale čiste ljubavi, ljubavnog zanosa i ljubavnog bola. Nadahnut idejama platonske ljubavi i anegdotama o toj ljubavi koje je imao prilike čitati kod Stendala, Hajne je mnoge od tih elemenata ugradio u svoje brojne pjesme, od kojih smo $u$ radu spomenuli one koje smo vidjeli kao najvažnije i najrelevantnije za predmet našeg interesovanja.

\section{IZVORI}

Ğamīl. (2008) Dīwân. Bayrūt: Dâr al-râtib al-ğami'iyya.

Hajne, H. (1989) Bio je divan mesec maj. Beograd: Bajat.

Hajne, H. (1964) Pesme. Beograd: Rad.

Hajne, H. (1975) Sve slobode - izabrane pesme. Beograd: Beogradski izdavačko-grafički zavod.

Heine, H. Briefe.

Mağnūn. (2008) Dīwân. Bayrūt: Dâr al-kitâb al-'arabī.

Šantić, A. (1923) Iz Hajneove lirike. Mostar: Knjižarnica Trifka dudića.

Šantić, A. (1996) Pesme. Sremski Karlovci: Kairos.

\section{LITERATURA}

Bajraktarević, F. (1956) Postanak Bašagićeve Ašiklije i problem pozajmica u književnosti. Zbornik Filozofskog fakulteta, str. 399-419.

Bajraktarević, F. (1938) Uticaj Istoka na Getea. Beograd.

Deretić, J. (2007) Istorija srpske književnosti. Zrenjanin: Sezam book.

Krivokapić, M. (2011) Nemačka književnost - članci i rasprave. Sremski Karlovci-Novi Sad.

Mehring, F. (1951) Heinrich Heine. Beograd-Zagreb. 
Pertschi, O. (2001) der Asra - ein bosnische Volkslied und/oder eine Ubersetzung aus Heine? Heine-Jahrbuch, str. 129-135.

Popović, T. (2007) Rečnik književnih termina. Beograd: Logos Art.

Stendal, A. B. (1976) O ljubavi. Subotica: Minerva.

al-Zabīdī, M. M. (1965) Tă̆ al-arūs. Kuwayt: Wizarāt al-iršād we al-anbā' fi al-Kuwayt.

Žmegač, V. Romantizam. U g. autora, Povijest svjetske književnosti (str. 104130). Zagreb: Mladost. 
Semir Rebronja, PhD

University of Zenica

Islamic Pedagogical Faculty

E-mail: r_semin@yahoo.com

\section{THE LOVE MOTIV IN UZRIT POETS AND HEINRICH HEINE POETRY}

\section{ABSTRACT}

The aim of the research is a comparative analysis of Uzrit and Heine's lyrics and, apropos, to examine the reasons and common factors of two literatures, one in the desert and the other in Europe. By analyzing the poems of Mağnün and Ğamil, on the one hand, and Heine, on the other, we are proving very close themes of love, as well as of poetic "pessimism." The poem Der Asra by the poet Heine was influenced by Arab Uzrit poets. It is found as the 15th song in Heine's series Poems and Ballads, and was composed in the period around 1845-1846. The Asra Poem is about the Uzrites, and Heine found inspiration for it in Arabic anecdotes about Uzrit love, which he read in Stendhal's famous book On Love (De l'amor, 1822). The basic theme for Uzrit poet is love, a woman, one and only woman who has captured his heart. That woman is the materialization of all poet's desires, goals, and aspirations. She is the center of his singing, and not just singing, she is the center of the poet's world. And Heine's lover is lonely, he longs, and it is a longing for distance, he personified his longing in a lonely pine tree in the north, which is longing for a palm tree that is far away, somewhere in the east, in the sands of the desert.

Key words: Uqrit poetry, romanticism, Heinrich Heine, comparative literature 
الأستاذ المشارك سمير ربرونيا

جامعة زنيستا

كلية التربية الإسلامية

r_semir@yahoo.com

\section{دوافع الحب لدى الشعراء العذريين وهاينرش هاينه}

\section{الخلاصة}

موضوع هذا البحث هو التحليل المقارن للشعر العذري وقصائد هاينه، وبالتالي استكشاف ألشاف

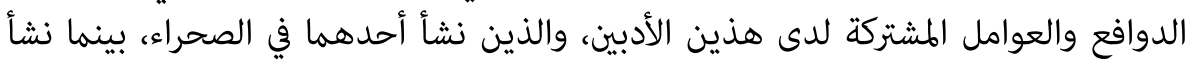

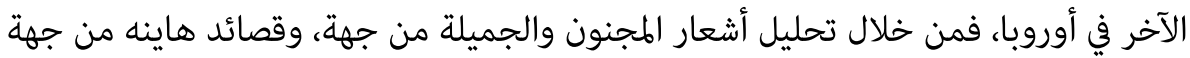

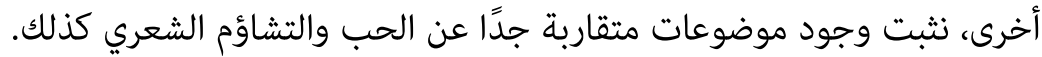
لقد تأثرت قصيدة دير أزرا للشاعر هاينه بالأشعار العذرية العربية، وهي تعتبر القصيدة

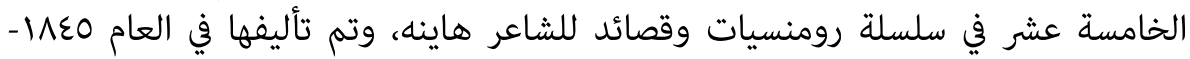

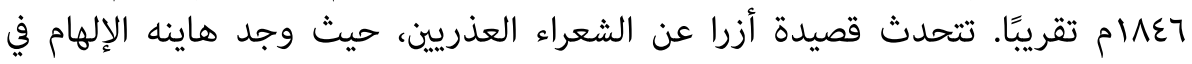

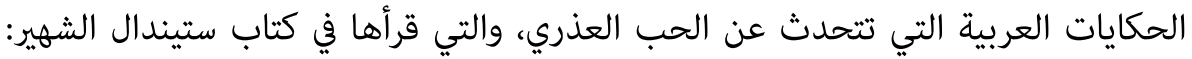

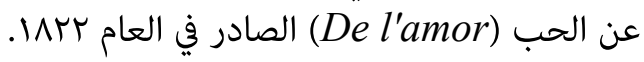

إن الموضوع الأساسي الذي يتحدث عنه الشاعر العذري هو الحب والمرأة، بل إنه يتحدث عن إنه

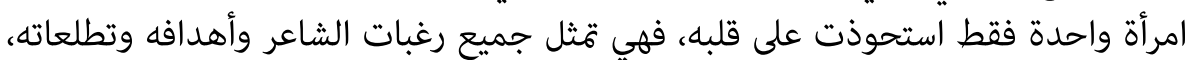

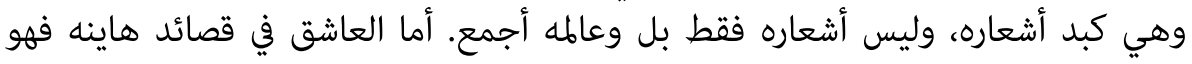

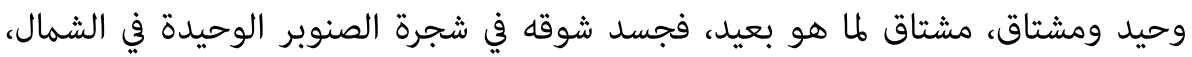
والتي تشتاق إلى نخلة بعيدة في مكان ما في الشرق، في في رماق فيد في شال الصحراء. الكلمات المفتاحية: الشعر العذري، الرومانسية، هاينرش هاينه، الأدب المقارن. 